\title{
Identification and Characterization of Colletotrichum Species Associated with Mango Anthracnose in Guangxi, China
}

Jianyou Mo, Institute of Plant Protection, Guangxi Academy of Agricultural Sciences, Nanning, Guangxi, 530007, China, and Guangxi Key Laboratory of Biology for Crop Diseases and Insect Pests, Nanning, Guangxi, 530007, China; Guang Zhao, Department of Guangxi Forestry Pest Management, Nanning, Guangxi, 530028, China; Qili Li, ${ }^{\dagger}$ Ghulam S. Solangi, Lihua Tang, Tangxun Guo, and Suiping Huang, Institute of Plant Protection, Guangxi Academy of Agricultural Sciences, Nanning, Guangxi, 530007, China, and Guangxi Key Laboratory of Biology for Crop Diseases and Insect Pests, Nanning, Guangxi, 530007, China; and Tom Hsiang, School of Environmental Sciences, University of Guelph, ON, Canada

\begin{abstract}
Mango (Mangifera indica) is widely grown across southern China, especially in the provinces of Guangxi, Hainan, Yunnan, Sichuan, and Taiwan. Guangxi itself has over 86,667 ha of mango production. The purpose of this study was to identify Colletotrichum species associated with mango in different parts of Guangxi and examine their pathogenicity on leaves and fruits of mango in vitro. Diseased leaves were collected from 25 mango orchards in different areas of Guangxi province. Sixtyfive isolates were obtained from mango leaves with anthracnose symptoms, and these were further characterized based on morphology and DNA sequencing. Twenty-nine isolates from different areas were selected for sequencing and analyses of the internal transcribed spacer region, glyceraldehyde-3-phosphate dehydrogenase, partial actin,

$\beta$-tubulin, and chitin synthase genomic regions. The most common fungal isolates were these three species: Colletotrichum asianum, $C$. fructicola, and $C$. siamense. $C$. asianum was the most common and widely distributed in Guangxi (51.7\%), followed by C. fructicola (37.9\%) and $C$. siamense (10.2\%), both found in Tiandong, Tianyang, and Wuming counties. There was no evidence of geographical specialization of the different species. Pathogenicity assays showed that all isolates were pathogenic to mango leaves and fruit (cultivar Tainong). No relationship was found between origin of isolates and their virulence. This is the first description of $C$. asianum, $C$. fructicola, and $C$. siamense as causal agents of mango leaf anthracnose from Guangxi province, China.
\end{abstract}

Mango, Mangifera indica (L.), is considered one of the most important tropical or subtropical fruit crops (Nelson 2008). In China, mango is cultivated mainly in southern and southwestern provinces. The planted area of mango was almost 130,000 ha, producing almost 900,000 tons in China during 2012 (Li et al. 2013). Guangxi province is the largest producing area of mango in China, and the mango industry contributes significantly to the local economy of Guangxi (Li et al. 2013). Anthracnose disease of mango caused by several Colletotrichum species is considered the most important disease of mango in China (Hong et al. 2016). Mango anthracnose is mainly caused by Colletotrichum gloeosporioides, but sometimes $C$. acutatum has also been reported as the causal agent (Freeman et al. 1998; Jayasinghe and Fernando 2009; Phoulivong et al. 2010). Mango anthracnose appears as irregularly shaped, black necrotic spots on upper and lower sides of mango leaves. Symptoms can also be found on stalks and flowers. Although many parts of the plant may be affected, the major losses occur during ripening and postharvest, when black lesions appear on mango fruit surfaces (Arauz 2000; Freeman et al. 1998).

Identification and characterization of Colletotrichum species is usually based on morphological characteristics (Hyde et al. 2009; Photita et al. 2005), such as conidial morphological, production of perithecia (Freeman et al. 2000), and sensitivity to benomyl (Valero et al. 2010). However, morphological differences are not sufficient to separate Colletotrichum species because there are differences for the

†Corresponding author: Qili Li; E-mail: 65615384@qq.com, liqili@gxaas.net

Funding: The research was supported by National Natural Science Foundation of China (Grant No. 31600029, 31560526), Guangxi Natural Science Foundation (Grant No. 2016GXNSFCB380004), Guangxi Key Laboratory of Biology for Crop Disease and Insect Pests (Grant No. 15-140-45-ST-2), and Foundation for Development of Science and Technology Guangxi Academy of Agricultural Sciences (2016JZ24, 2017JZ01).

Accepted for publication 29 December 2017.

(c) 2018 The American Phytopathological Society same specimen when grown in the lab and under different growth conditions. Hence, molecular techniques are needed to separate species of Colletotrichum and to examine genetic variation within and between species and populations (Cai et al. 2009; Hyde et al. 2009; Phoulivong et al. 2010). Studies on the systematics of Colletotrichum species recently have placed species of this genus into nine major clades plus small clusters and isolated species, with clades probably representing species complexes (Cannon et al. 2012).

The internal transcribed spacer region (ITS) of ribosomal DNA has been frequently used to separate Colletotrichum species (Freeman et al. 2000) but not always satisfactorily (Cannon et al. 2012). Other markers, such as actin (ACT), $\beta$-tubulin (TUB2), chitin synthase 1 (CHS-1), and glyceraldehyde-3-phosphate dehydrogenase (GAPDH) gene have been used to resolve relationships among Colletotrichum species (Weir et al. 2012). Considering recent changes in classification of Colletotrichum species, and the lack of information on the identity and characteristics of isolates causing mango anthracnose in China, the objectives of this study were as follows: (i) identify and characterize species of Colletotrichum associated with mango anthracnose in Guangxi, China, based on morphology and DNA sequence comparisons; (ii) examine virulence of isolates from different parts of Guangxi province and whether there are geographical differences; and (iii) investigate relationships among isolates of Colletotrichum spp. from mango using sequences of ITS, ACT, TUB2, CHS-1, and GAPDH.

\section{Materials and Methods}

Fungal isolation. Mango leaves with symptoms of anthracnose were collected from production fields of six counties (Tiandong, Tianyang, Tianlin, Youjiang, Wuming, and Qinzhou) in Guangxi province, ranging over an area of 450 by $300 \mathrm{~km}$. Small $(3 \times 3-\mathrm{mm})$ sections were cut from lesion margins and were surface sterilized in $75 \%$ ethanol for $15 \mathrm{~s}$ and $0.1 \%(\mathrm{v} / \mathrm{v})$ mercuric chloride for $45 \mathrm{~s}$, followed by rinses in sterile water. The sections were then plated onto potato dextrose agar (PDA) and incubated at $25^{\circ} \mathrm{C}$. Fungal growth was examined daily up to 14 days. Isolates were subcultured onto fresh PDA and purified by single-spore culture. Isolates were stored on PDA slants at $4^{\circ} \mathrm{C}$. 
Morphological characterization. Isolates were cultured on PDA plates at $25^{\circ} \mathrm{C}$ under continuous fluorescent light for 5 days. Plugs (6-mm diameter) from colony margins were placed in the center of each 90-mm-diameter plate with four replications. The colony color and culture diameters (two perpendicular directions) were recorded after 3,7 , and 10 days at $25^{\circ} \mathrm{C}$. Colony diameters were used to calculate hyphal growth rate $\left(\mathrm{mm} /\right.$ day). Isolates were incubated at $25^{\circ} \mathrm{C}$ for 21 days on PDA plates to examine conidial production and the shape and size of conidia. The length and width of 150 conidia per isolate were measured.

DNA isolation, polymerase chain reaction (PCR), and sequencing. Isolates were cultured on PDA in Petri plates overlaid with cellophane for 7 days at $25^{\circ} \mathrm{C}$. Mycelia were harvested with a flamed spatula, and genomic DNA of the isolates was extracted with the cetyltrimethyl ammonium bromide method (Taylor et al. 1993). All strains in this study were subjected to analysis of the rDNA-ITS, partial GAPDH, partial ACT, partial TUB2, and partial CHS-1 genomic regions (Table 1). PCR amplification of GAPDH was done using the primers GDF1 and GDR1 (Templeton et al. 1992) and that of CHS-1 with CHS79F and CHS354R (Carbone and Kohn 1999). The partial ACT, TUB2, and ITS regions were amplified with the primer pairs ACT512F and ACT783R (Carbone and Kohn 1999), T1 and Bt2b (Glass and Donaldson 1995), and ITS1 and ITS4 (White et al. 1990), respectively. All PCR reactions were conducted in $50-\mu 1$ volumes containing $1 \times$ PCR buffer, $0.2 \mathrm{mM}$ concentrations of each dNTP, $4 \mathrm{mM} \mathrm{MgCl}_{2}, 0.5 \mu \mathrm{M}$ concentrations of each

Table 1. Primers used for PCR amplification and DNA sequencing

\begin{tabular}{llll}
\hline Gene $^{\mathbf{z}}$ & \multicolumn{1}{c}{ Primer } & \multicolumn{1}{c}{ Primer sequences } & References \\
\hline Actin & ACT-512F & ATGTGCAAGGCCGGTTTCGC & Carbone and Kohn (1999) \\
& ACT-783R & TACGAGTCCTTCTGGCCCAT & Guerber et al. (2003) \\
GAPDH & GDF1 & GCCGTCAACGACCCCTTCATTGA & Templeton et al. (1992) \\
& GDR1 & GGGTGGAGTCGTACTTGAGCATGT & Carbone and Kohn (1999) \\
CHS-1 & CHS I-79F & TGGGGCAAGGATGCTTGGAAGAAG & O'Donnell et al. (2000) \\
& CHS I-354R & TGGAAGAACCATCTGTGAGAGTTG & Glass and Donaldson (1995) \\
ITS Tubulin & T1 & AACATGCGTGAGATTGTAAGT & White et al. (1990) \\
& It2b & ACCCTCAGTGTAGTGACCCTTGGC & \\
\hline
\end{tabular}

${ }^{\mathrm{z}} \mathrm{GAPDH}=$ glyceraldehyde-3-phosphate dehydrogenase; CHS-1 = chitin synthase; and ITS = rDNA internal transcribed spacer region.

Table 2. Sequences of Colletotrichum isolates used in the phylogenetic study

\begin{tabular}{|c|c|c|c|c|c|c|c|c|}
\hline \multirow[b]{2}{*}{ Species } & \multirow[b]{2}{*}{ Culture $^{y}$} & \multirow[b]{2}{*}{ Host } & \multirow[b]{2}{*}{ Country } & \multicolumn{5}{|c|}{ GenBank accession numbers ${ }^{\mathrm{z}}$} \\
\hline & & & & ITS & GAPDH & ACT & CHS-1 & TUB2 \\
\hline \multirow[t]{2}{*}{ C. asianum } & IMI 313839 & Mangifera indica & Australia & JX010192 & JX009915 & JX009576 & JX009753 & JX010384 \\
\hline & ICMP 18580 & Coffea arabica & Thailand & FJ972612 & JX010053 & JX009584 & JX009867 & JX010406 \\
\hline \multirow{2}{*}{ C. fructicola } & ICMP 18613 & Limonium sinuatum & Israel & JX010167 & JX009998 & JX009491 & JX009772 & JX010388 \\
\hline & ICMP 18727 & Fragaria ananassa & U.S.A. & JX010179 & JX010035 & JX009565 & JX009812 & JX010394 \\
\hline \multirow[t]{2}{*}{ C. ignotum } & CBS 125397 & Tetragastris panamensis & Panama & JX010173 & JX010032 & JX009581 & JX009874 & JX010409 \\
\hline & UASB-Cg-50 & Pepper & India & JN248667 & JN861219 & JN861154 & KC790583 & JN861169 \\
\hline \multirow[t]{3}{*}{ C. siamense } & ICMP 12567 & Persea americana & Australia & JX010250 & JX009940 & JX009541 & JX009761 & JX010387 \\
\hline & ICMP 17795 & Malus domestica & U.S.A. & JX010162 & JX010051 & JX009506 & JX009805 & JX010393 \\
\hline & ICMP 18121 & Dioscorea rotundata & Nigeria & JX010245 & JX009942 & JX009460 & JX009845 & JX010402 \\
\hline C. gloeosporioides & IMI 356878 & Citrus sinensis & Italy & JX010152 & JX010056 & JX009531 & JX009818 & JX010445 \\
\hline C. acutatum & CBS 126521 & Anemone hybride & Netherlands & JQ948366 & JQ948697 & JQ949687 & JQ949027 & JQ950017 \\
\hline C. aenigma & ICMP 18686 & Pyrus pyrifolia & Japan & JX010243 & JX009913 & JX009519 & JX009789 & JX010390 \\
\hline C. aeschynomenes & $\begin{array}{l}\text { ICMP 17673*, } \\
\text { ATCC } 201874\end{array}$ & Aeschynomene virginica & U.S.A. & JX010176 & JX009930 & JX009483 & JX009799 & JX010392 \\
\hline C. alienum & IMI 313842, ICMP 18691 & Persea americana & Australia & JX010217 & JX010018 & JX009580 & JX009754 & JX010385 \\
\hline C. nupharicola & CBS 469.96, ICMP 17938 & $\begin{array}{l}\text { Nuphar lutea subsp. } \\
\text { polysepala }\end{array}$ & U.S.A. & JX010189 & JX009936 & JX009486 & JX009834 & JX010397 \\
\hline C. queenslandicum & ICMP $1778^{*}$ & Carica papaya & Australia & JX010276 & JX009934 & JX009447 & JX009899 & JX010414 \\
\hline C. aotearoa & ICMP 18532 & Vitex lucens & New Zealand & JX010220 & JX009906 & JX009544 & JX009764 & JX010421 \\
\hline C. тиsаe & $\begin{array}{r}\text { CBS } 116870^{*}, \\
\text { ICMP } 19119\end{array}$ & Musa sp. & U.S.A. & JX010146 & JX010050 & JX009433 & JX009896 & HQ596280 \\
\hline C. salsolae & ICMP 19051* & Salsola tragus & Hungary & JX010242 & JX009916 & JX009562 & JX009863 & JX010403 \\
\hline $\begin{array}{l}\text { C. siamense } \\
\text { (syn. } C \text {. } \\
\text { hymenocallidis) }\end{array}$ & $\begin{array}{l}\text { CBS } 125378(*), \\
\text { ICMP } 18642\end{array}$ & Hymenocallis americana & China & JX010278 & JX010019 & GQ856775 & GQ856730 & JX010410 \\
\hline C. $t i$ & ICMP 5285 & Cordyline australis & New Zealand & JX010267 & JX009910 & JX009553 & JX009897 & JX010441 \\
\hline C. theobromicola & ICMP 18566 & Olea europaea & Australia & JX010282 & JX009953 & JX009496 & JX009801 & JX010376 \\
\hline C. xanthorrhoeae & $\begin{array}{c}\text { BRIP } 45094^{*}, \\
\text { ICMP } 17903, \\
\text { CBS } 127831 \\
\end{array}$ & Xanthorrhoea preissii & Australia & JX010261 & JX009927 & JX009478 & JX009823 & JX010448 \\
\hline
\end{tabular}


primer, 0.5 units of Taq DNA polymerase (Takara), and $1 \mu \mathrm{l}$ of template DNA (20 ng/ $\mu \mathrm{l})$. The PCR program for GAPDH, ACT, and TUB2 included a denaturation step at $94^{\circ} \mathrm{C}$ for $2 \mathrm{~min}$, followed by 35 cycles at $94^{\circ} \mathrm{C}$ for $45 \mathrm{~s}, 60^{\circ} \mathrm{C}$ for $45 \mathrm{~s}$, and $72^{\circ} \mathrm{C}$ for $1 \mathrm{~min}$, and a final cycle at $72^{\circ} \mathrm{C}$ for $10 \mathrm{~min}$. The PCR program for the ITS region included a 2-min denaturing step at $94^{\circ} \mathrm{C}$ followed by 34 cycles at $94^{\circ} \mathrm{C}$ for $1 \mathrm{~min}, 55^{\circ} \mathrm{C}$ for $30 \mathrm{~s}$, and $72^{\circ} \mathrm{C}$ for $1 \mathrm{~min}$, and a final cycle of $10 \mathrm{~min}$ at $72^{\circ} \mathrm{C}$. The amplification products were sent to Shanghai Sangon Company for purification and sequencing. Sequences of mango Colletotrichum isolates obtained from Guangxi were submitted to GenBank.

Phylogenetic analyses. Sequences were edited and assembled using DNAMAN (version 5.2.2; Lynnon Biosoft) to produce consensus sequences that were compared by BLAST (Altschul et al. 1990) against the NCBI nonredundant database. Sequences from extype or ex-epitype isolates of Colletotrichum species from GenBank were selected for use in the phylogenetic analyses (Table 2). Sequence alignments of each gene and combined genes were made with ClustalX version 1.83. Phylogenetic trees were constructed with MEGA4 software version 4.0 using the maximum parsimony method.

Pathogenicity and virulence on mango tissues. Select isolates were used for pathogenicity and virulence tests on detached fruits and leaves of mango (cultivar Tainong) in controlled conditions. Isolates were incubated on PDA plates for 7 to 10 days at $25^{\circ} \mathrm{C}$ in the laboratory. Fresh young leaves and fresh harvested mango fruits without visible disease from Tiandong, Guangxi, were used for inoculation. The leaves and mango fruits were washed with running water, surface sterilized in $70 \%$ ethanol for $30 \mathrm{~s}$ and $1 \% \mathrm{NaClO}$ for $1 \mathrm{~min}$, and finally rinsed with sterile distilled water.

After air drying, detached young healthy leaves $(12$ to $15 \mathrm{~cm})$ were placed into plastic containers $(252 \times 174 \times 93 \mathrm{~mm})$ lined with moist absorbent paper and, and six stab wounds were made in the midregion forming a circle with a $5 \mathrm{~mm}$ diameter using a sterilized needle.
Hyphal plugs from actively growing margins of PDA cultures were placed on each wound spot on the leaves. The experiment was completely randomized with three replicates per isolate involving five leaves per replicate. Fifteen leaves were inoculated for each isolate, and in controls, leaves were treated with sterile agar plugs. The containers were partially sealed in plastic and incubated at $25^{\circ} \mathrm{C}$ in the dark in a growth chamber. Virulence was assessed by measuring lesion length at 7 days post inoculation (DPI) in two perpendicular directions on each leaf.

After washing and air drying, nearly ripened mango fruits $(\sim 200 \mathrm{~g})$ were wounded in the protruding fleshy parts by stabbing with a flamed needle through the skin a depth of $3 \mathrm{~mm}$, again forming a circle with a $5 \mathrm{~mm}$ diameter. Mycelial plugs of 6- $\mathrm{mm}$ diameter from PDA cultures were placed on wound sites. Control treatments used sterile agar plugs. Inoculated fruits were placed in plastic containers $(252 \times 174 \times 93 \mathrm{~mm})$ overlaid with moist absorbent paper to maintain humidity. The containers were placed in unsealed bags and incubated at $25^{\circ} \mathrm{C}$ in the dark. Fruits were checked for development of symptoms up to 10 days. Isolates were considered pathogenic when lesions expanded beyond the 5-mm diameter initial wound site. Virulence was evaluated by measuring lesion length at 10 DPI in two perpendicular directions. Significant differences in virulence caused were assessed by an analysis of variance, and when significant treatment effects were found, means were compared by $\operatorname{LSD}(P=0.05)$ using Data Processing System software (DPS 3.0) for Windows (Zhejiang University, Hangzhou, China).

\section{Results}

Fungal isolation. From 2011 to 2014, leaves of mango with anthracnose symptoms were collected from 25 mango orchards in Guangxi province, China. At least one isolate from each field was chosen for further analysis. In total, 65 Colletotrichum isolates were obtained from different areas of Guangxi, and 29 single-spore

Table 3. Mango isolates of Colletotrichum spp. from Guangxi used in the study and their GenBank accession numbers for several genomic regions

\begin{tabular}{|c|c|c|c|c|c|c|c|}
\hline \multirow[b]{2}{*}{ Isolate } & \multirow[b]{2}{*}{ Species } & \multirow[b]{2}{*}{ Geographic area } & \multicolumn{5}{|c|}{ GenBank accession numbers ${ }^{\mathrm{z}}$} \\
\hline & & & ACT & TUB2 & GAPDH & CHS-1 & ITS \\
\hline$\overline{\mathrm{NN} 19}$ & C. asianum & Tuanluo, Nanning & MF039745 & MF039774 & MF040763 & MF039803 & MF039832 \\
\hline WM52 & C. asianum & Lijian, Wuming & MF039746 & MF039775 & MF040764 & MF039804 & MF039833 \\
\hline QZ-3 & C. asianum & Wuli, Lingshan & MF039747 & MF039776 & MF040765 & MF039805 & MF039834 \\
\hline TD6-7 & C. asianum & Sitang, Tiandong & MF039748 & MF039777 & MF040766 & MF039806 & MF039835 \\
\hline NN133 & C. asianum & Dingdang, Long' an & MF039749 & MF039778 & MF040767 & MF039807 & MF039836 \\
\hline LY12 & C. asianum & Junting, Lingyun & MF039750 & MF039779 & MF040768 & MF039808 & MF039837 \\
\hline LA130 & C. asianum & Dingdang, Long'an & MF039751 & MF039780 & MF040769 & MF039809 & MF039838 \\
\hline LA1 & C. asianum & Tanliang, Long'an & MF039752 & MF039781 & MF040770 & MF039810 & MF039839 \\
\hline NN105 & C. asianum & Jinlin, Nanning & MF039753 & MF039782 & MF040771 & MF039811 & MF039840 \\
\hline NN8 & C. asianum & Guangxi Subtropical Crops Research Institute & MF039754 & MF039783 & MF040772 & MF039812 & MF039841 \\
\hline BS13 & C. asianum & Youjiang, Baise & MF039755 & MF039784 & MF040773 & MF039813 & MF039842 \\
\hline NN7 & C. asianum & Guangxi Academy of Agricultural Sciences & MF039756 & MF039785 & MF040774 & MF039814 & MF039843 \\
\hline TL110 & C. asianum & Leli, Tianlin & MF039757 & MF039786 & MF040775 & MF039815 & MF039844 \\
\hline TL107 & C. asianum & Leli, Tianlin & MF039757 & MF039787 & MF040776 & MF039816 & MF039845 \\
\hline NKY-1 & C. asianum & Guangxi Academy of Agricultural Sciences & MF039758 & MF039788 & MF040777 & MF039817 & MF039846 \\
\hline WM01-2 & C. fructicola & Lijian, Wuming & MF039759 & MF039789 & MF040778 & MF039818 & MF039847 \\
\hline LZ120 & C. fructicola & Longzhou, Chongzuo & MF039760 & MF039790 & MF040779 & MF039819 & MF039848 \\
\hline NN10 & C. fructicola & Tunli, Nanning & MF039761 & MF039791 & MF040780 & MF039820 & MF039849 \\
\hline TD6-5 & C. fructicola & Sitang, Tiandong & MF039762 & MF039792 & MF040781 & MF039821 & MF039850 \\
\hline TD1 & C. fructicola & Pingma, Tiandong & MF039763 & MF039793 & MF040782 & MF039822 & MF039851 \\
\hline TL111 & C. fructicola & Leli, Tianlin & MF039764 & MF039794 & MF040783 & MF039823 & MF039852 \\
\hline NN20 & C. fructicola & Tanluo, Nanning & MF039765 & MF039795 & MF040784 & MF039824 & MF039853 \\
\hline TD8 & C. fructicola & Pingma, Tiandong & MF039766 & MF039796 & MF040785 & MF039825 & MF039854 \\
\hline WM03-1 & C. fructicola & Lijian, Wuming & MF039767 & MF039797 & MF040786 & MF039826 & MF039855 \\
\hline TD7 & C. fructicola & Sitang, Tiandong & MF039768 & MF039798 & MF040787 & MF039827 & MF039856 \\
\hline TD4 & C. fructicola & Pingma, Tiandong & MF039769 & MF039799 & MF040788 & MF039828 & MF039857 \\
\hline TD3 & C. siamense & Silin, Tiandong & MF039770 & MF039800 & MF040789 & MF039829 & MF039858 \\
\hline TY9 & C. siamense & Tianzhou, Tianyang & MF039771 & MF039801 & MF040790 & MF039830 & MF039859 \\
\hline WM03-2 & C. siamense & Lijian, Wuming & MF039772 & MF039802 & MF040791 & MF039831 & MF039860 \\
\hline
\end{tabular}

${ }^{\mathrm{z}} \mathrm{ACT}=$ actin gene; TUB2 $=\beta$-tubulin; GAPDH = glyceraldehyde-3-phosphate dehydrogenase CHS-1 = chitin synthase; and ITS = rDNA internal transcribed spacer region. 
isolates were used for further study (Table 3) (one isolate from each orchard, but for some large orchards more than one isolate was chosen for further study). Among the 29 isolates, 15 were identified as $C$. asianum, 11 as $C$. fructicola, and 3 as $C$. siamense using morphological and molecular methods. Other species isolated such as species of Alternaria, Phomopsis, Botryosphaeria, or Pestalotia were not considered further in this study.
Phylogenetic analyses. In the present study, 29 isolates from different areas were selected for sequencing and analyses of ITS, GAPDH, ACT, TUB2, and CHS-1. BLASTn searches of generated DNA sequences from 15 isolates against GenBank showed high similarity ( $>99 \%$ ) with the sequences of $C$. asianum, 11 isolates showed high similarity with the sequences of $C$. fructicola, and 3 isolates showed high similarity (99 or $100 \%$ ) with the sequences of $C$. siamense.



Fig. 1. Phylogenetic tree using sequences of 29 Colletotrichum isolates from mango trees in Guangxi and from extype or ex-epitype isolates in GenBank using combined internal transcribed spacer, actin, glyceraldehyde-3-phosphate dehydrogenase, $\beta$-tubulin, and chitin synthase 1 genes. Bootstrap values $>50 \%(1,000$ replication) are given at the nodes. Colletotrichum acutatum was used as the outgroup. Isolates from this study are emphasized in bold. 
ACT, TUB2, CHS-1, GAPDH, and ITS sequences of Colletotrichum from mango trees in Guangxi province were submitted to GenBank (Table 3) and aligned with GenBank sequences of Colletotrichum species from different hosts and other countries (Table 2). The gene boundaries in the alignment were as follows: ACT (282 to $289 \mathrm{bp}$ ), TUB2 (699 to $701 \mathrm{bp}$ ), CHS-1 (299 bp), GAPDH (277 to $280 \mathrm{bp}$ ), and ITS (546 bp).

A phylogenetic tree of 29 Colletotrichum isolates from this study and sequences from extype or ex-epitype isolates from GenBank using combined ITS, ACT, GAPDH, TUB2, and CHS-1 genes with maximum parsimony analysis is shown in Figure 1. The combined data set produced three well-separated clades. Fifteen Colletotrichum isolates composed a highly supported clade ( $99 \%$ bootstrap support) with $C$. asianum isolates ICMP18580 from Coffea arabica in Thailand and IMI313839 from Mangifera indica in Australia. Eleven isolates composed a supported clade (69\% bootstrap support) with
C. fructicola isolates ICMP18727, ICMP18613, and ICMP12568 and C. ignotum (= C. fructicola) isolates ICMP125397 and UASB-Cg-50. Three isolates composed a supported clade (51\% bootstrap support), which closed with $C$. siamense isolate ICMP17795.

The diversity analyses from 29 isolates of Colletotrichum species showed the following distribution: 15 isolates (51.7\%) belonging to $C$. asianum, 11 isolates $(37.9 \%)$ to $C$. fructicola, and 3 isolates (10.2\%) to C. siamense.

Morphological and cultural characterization. All tested isolates developed white colonies that turned to gray to black after 14 days on PDA (Fig. 2). Colony sectoring was observed in 8 of 29 isolates. There was considerable variation in mycelial growth rate among the 29 isolates of Colletotrichum (Table 2). The average mycelial growth rate for $C$. asianum was 6.7 to $10.7 \mathrm{~mm} /$ day, for $C$. fructicola, 7.3 to $12.4 \mathrm{~mm} / \mathrm{day}$, and for $C$. siamense, 9.4 to $11.1 \mathrm{~mm} / \mathrm{day}$. Conidia were all hyaline, guttulate, one-celled, and cylindrical. The
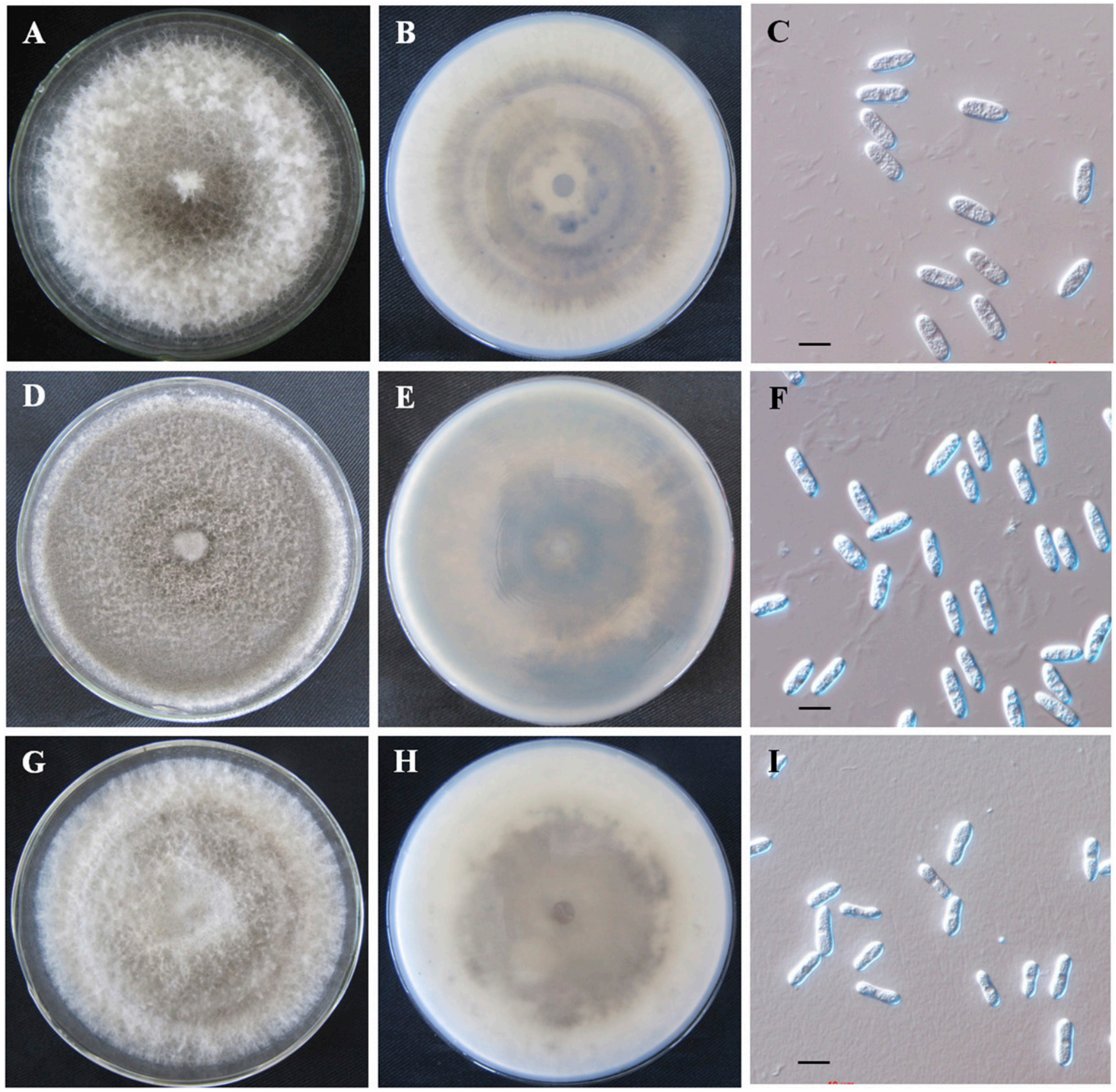

Fig. 2. Morphological characteristics of colonies and conidia of mango Colletotrichum isolates from Guangxi. Upper (A) and reverse (B) sides of C. asianum NN8 PDA plate at 14 days after inoculation; and conidia of $C$. asianum (C). Upper (D) and reverse (E) sides of C. fructicola isolate WM01-2 culture on PDA 14 days after inoculation; and conidia of C. fructicola (F). Upper $(\mathbf{G})$ and reverse $(\mathbf{H})$ sides of $C$. siamense isolate TY9 culture on PDA 14 days after inoculation; and conidia of $C$. siamense $(\mathbf{I})$. Bars: $10 \mu \mathrm{m}$. 
average conidial sizes for isolates were $C$. asianum, 12.1 to $18.6 \times 4.2$ to $5.6 \mu \mathrm{m}$; $C$. fructicola, 14.1 to $20.2 \times 3.7$ to $4.3 \mu \mathrm{m}$; and $C$. siamense, 15.0 to $18.5 \times 5.0$ to $5.5 \mu \mathrm{m}$. The various Colletotrichum species reported here showed differences in conidial size and growth rates (Table 4).

Pathogenicity and virulence in tissues. All 29 tested isolates were pathogenic to mango leaves and fruits. Ripened fruits with anthracnose develop sunken, dark brown to black decay. The virulence of the 29 isolates of Colletotrichum from Guangxi province showed significant differences, with lesion diameters ranging from 7.0 to $30.0 \mathrm{~cm}$ on leaves and from 6 to $21 \mathrm{~mm}$ on fruits. The lesion diameter of $C$. asianum on leaves ranged from 9.2 to $28.2 \mathrm{~mm}$ and on fruits ranged from 6.2 to $21 \mathrm{~mm}$. For $C$. fructicola it was 8.8 to $30.0 \mathrm{~mm}$ on leaves and 5.8 to $13.6 \mathrm{~mm}$ on fruits. For $C$. siamense it was 7.0 to $22.2 \mathrm{~mm}$ on leaves and 6.0 to $6.5 \mathrm{~mm}$ on fruits. The virulence of $C$. fructicola isolates TD1 and TD4 from the same field showed significant differences $(P \leq 0.05)$ (Table 4$)$.

\section{Discussion}

This is the first report characterizing Colletotrichum species associated with anthracnose of mango in Guangxi province, China, using morphological identification and phylogenetic analysis. The morphological features of the isolates agreed with the description of C. gloeosporioides, but cultural characteristics, which may be diverse owing to cultural conditions, and conidial morphology cannot distinguish between species within the $C$. gloeosporioides complex (Weir et al. 2012). Based on morphological identification, single gene sequence analysis, and the five-gene combined phylogenetic analysis, the isolates obtained from mango in Guangxi included in this study belong to the $C$. gloeosporioides complex. $C$. gloeosporioides has previously been shown to be the causal agent of tropical fruit rots including mango, and the present study showed that all 29 isolates from mango leaves with anthracnose symptoms across a 450 by $300 \mathrm{~km}$ region belonged to the species complex $C$. gloeosporioides. In the contrast, Phoulivong et al. (2010) reported that $C$. gloeosporioides was not a common pathogen in the tropics and was not the cause of mango anthracnose in Thailand or Laos.

The species complex $C$. gloeosporioides has been separated into many different species (Weir et al. 2012). Three species were found to be associated with mango leaf anthracnose: $C$. asianum, $C$. fructicola, and $C$. siamense. These species have also been previously recorded from mango in Brazil (Phoulivong et al. 2010). Among the genomic regions tested, $C$. asianum, $C$. fructicola, and $C$. siamense could be separated by all except for ITS. This does not agree with the results of Weir et al. (2012), who found $C$. asianum can be separated from these other taxa using any of the genes tested, including ITS. ITS sequences do not reliably separate $C$. asianum, $C$. siamense, and C. fructicola, but $C$. siamense and $C$. fructicola can be distinguished using TUB2, and this agrees with the previous reports (Weir et al. 2012).

C. asianum was well separated using five-gene combined phylogenetic analysis in this study, and it was the predominant species associated with mango in Guangxi, South China, in agreement with Vieira et al. (2014), who found that $C$. asianum was the most common endophytic species from mango trees. C. asianum is a wellknown pathogen of mangoes from India, Australia, Panama, and Thailand (Sharma et al. 2015).

Table 4. Morphological and virulence descriptions of Colletotrichum isolates from mango trees in Guangxi, China

\begin{tabular}{|c|c|c|c|c|}
\hline Isolate & Conidial size $(\mu \mathrm{m})^{\mathbf{x}}$ & $\begin{array}{l}\text { Mycelial growth } \\
(\mathbf{m m} / \text { day })^{\mathbf{y}}\end{array}$ & $\begin{array}{l}\text { Lesion diameter on mango } \\
\text { leaves }(\mathrm{mm})^{\mathrm{z}}\end{array}$ & $\begin{array}{l}\text { Lesion diameter on } \\
\text { mango fruit }(\mathrm{mm})^{\mathrm{z}}\end{array}$ \\
\hline \multicolumn{5}{|l|}{ C. asianum } \\
\hline NN19 & $18.6 \pm 0.5 \times 5.6 \pm 0.3$ & 8.4 bcdef & $12.6 \mathrm{bcd}$ & $18.2 \mathrm{hi}$ \\
\hline WM52 & $17.8 \pm 0.6 \times 4.4 \pm 0.3$ & $7.9 \mathrm{bc}$ & 14.4 bcde & 12.0 abcdefg \\
\hline TL107 & $17.3 \pm 1.0 \times 6.0 \pm 0.4$ & 9.2 efghi & $28.2 \mathrm{ij}$ & 11.5 abcdefg \\
\hline TL110 & $16.4 \pm 0.6 \times 5.8 \pm 0.3$ & 9.5 fghij & 14.0 bcde & 9.7 abcdef \\
\hline BS13 & $15.6 \pm 0.5 \times 6.5 \pm 0.4$ & 8.3 bcde & $9.2 \mathrm{~b}$ & 13.5 defgh \\
\hline NN7 & $15.5 \pm 0.4 \times 4.7 \pm 0.2$ & 8.4 bcdef & 15.4 bcdef & 8.9 abcde \\
\hline LA1 & $15.2 \pm 0.6 \times 5.7 \pm 0.3$ & 8.9 cdefg & $24.8 \mathrm{hij}$ & 12.4 bcdefg \\
\hline LY12 & $15.2 \pm 0.5 \times 4.9 \pm 0.3$ & 9.1 defgh & 14.2 bcde & $6.3 \mathrm{ab}$ \\
\hline QZ-3 & $14.2 \pm 0.8 \times 5.8 \pm 0.3$ & $10.7 \mathrm{klmn}$ & $26.2 \mathrm{hij}$ & $15.2 \mathrm{fgh}$ \\
\hline NN105 & $13.3 \pm 0.5 \times 4.6 \pm 0.2$ & $8.2 \mathrm{bcd}$ & 20.4 efgh & $6.2 \mathrm{ab}$ \\
\hline LA130 & $13.1 \pm 0.5 \times 5.2 \pm 0.4$ & 8.3 bcde & 20.2 efgh & 9.5 abcdef \\
\hline NN8 & $12.9 \pm 0.4 \times 4.8 \pm 0.2$ & $6.7 \mathrm{a}$ & 16.6 cdefg & $16.6 \mathrm{gh}$ \\
\hline TD6-7 & $12.4 \pm 0.6 \times 5.3 \pm 0.3$ & $10.5 \mathrm{jklmn}$ & $24.0 \mathrm{hij}$ & $21.1 \mathrm{i}$ \\
\hline NN133 & $12.1 \pm 0.5 \times 4.2 \pm 0.3$ & $7.9 \mathrm{bc}$ & 14.6 bcde & 12.6 cdefg \\
\hline NKY-1 & $16.7 \pm 0.3 \times 4.6 \pm 0.3$ & 9.9 hijkl & $30.0 \mathrm{j}$ & $15.1 \mathrm{fgh}$ \\
\hline \multicolumn{5}{|l|}{ C. fructicola } \\
\hline TL111 & $20.2 \pm 0.4 \times 4.3 \pm 0.3$ & $10.7 \mathrm{jklmn}$ & 22.0 fghi & $12.1 \mathrm{abc}$ \\
\hline TD6-5 & $16.9 \pm 0.3 \times 4.8 \pm 0.3$ & $7.3 \mathrm{ab}$ & $8.8 \mathrm{~b}$ & $6.3 \mathrm{ab}$ \\
\hline TD4 & $15.4 \pm 0.6 \times 5.2 \pm 0.4$ & $10.3 \mathrm{ijklm}$ & $9.0 \mathrm{~b}$ & 7.9 abcd \\
\hline TD7 & $15.3 \pm 0.5 \times 4.9 \pm 0.2$ & 10.9 lmno & $26.0 \mathrm{hij}$ & 10.9 abcdef \\
\hline WM03-1 & $15.2 \pm 0.3 \times 4.0 \pm 0.2$ & 9.7 ghijk & $25.0 \mathrm{hij}$ & 13.6 defgh \\
\hline TD8 & $15.0 \pm 0.5 \times 5.3 \pm 0.4$ & $10.8 \mathrm{klmn}$ & 23.0 ghij & 8.7 abcde \\
\hline NN20 & $14.6 \pm 0.7 \times 4.6 \pm 0.3$ & 11.7 nop & $30.0 \mathrm{j}$ & 7.9 abcd \\
\hline TD1 & $14.1 \pm 0.8 \times 3.7 \pm 0.4$ & 11.9 op & 22.2 fghi & $7.0 \mathrm{abc}$ \\
\hline NN10 & $20.1 \pm 0.5 \times 4.2 \pm 0.2$ & 9.4 fghij & 13.6 bcde & $5.8 \mathrm{a}$ \\
\hline WM01-2 & $17.2 \pm 0.5 \times 5.4 \pm 0.2$ & $12.4 \mathrm{p}$ & 18.8 defgh & 10.9 abcdefg \\
\hline LZ120 & $14.9 \pm 0.6 \times 4.1 \pm 0.2$ & 9.5 ghijk & 19.8 defgh & $6.8 \mathrm{abc}$ \\
\hline \multicolumn{5}{|l|}{ C. siamense } \\
\hline TY9 & $18.5 \pm 0.3 \times 5.0 \pm 0.3$ & $11.1 \mathrm{mno}$ & 22.2 fghi & 6.5 abcdefg \\
\hline TD3 & $15.4 \pm 0.5 \times 4.2 \pm 0.1$ & $10.4 \mathrm{ijklm}$ & $7.0 \mathrm{a}$ & $6.0 \mathrm{a}$ \\
\hline WM03-2 & $15.0 \pm 0.5 \times 5.5 \pm 0.3$ & 9.4 fghij & $10.6 \mathrm{bc}$ & $14.4 \mathrm{efgh}$ \\
\hline
\end{tabular}

${ }^{x}$ The length and width of 150 conidia per isolate on PDA were measured after 21 days at $25^{\circ} \mathrm{C}$.

y The colony diameter $(\mathrm{mm})$ was measured in two perpendicular directions. The colony diameter data were used to calculate the mycelial growth rate (mm/day).

${ }^{\mathrm{z}}$ The virulence of the isolates was evaluated by measuring lesion length at 7 and 10 days postinoculation in two perpendicular directions on leaves and fruits, respectively. 
C. fructicola is diverse morphologically and geographically. The species has been found on coffee berries (Thailand), Pyrus pyrifolia (Japan), Limonium (Israel), Malus sp. and Fragaria $\times$ ananassa (U.S.A.), Persea americana (Australia), Ficus sp. (Germany), Malus sp. (Brazil), Dioscorea sp. (Nigeria), Theobroma sp. and Tetragastris sp. (Panama) (Weir et al. 2012), and Vitis sp. (China) (Peng et al. 2013). C. fructicola has been described in association with mango in Brazil and Korea (Joa et al. 2016); however, this is the first report of C. fructicola infecting mango in China. C. ignotum $=C$. fructicola (Weir et al. 2012), and our genetic analyses showed the isolates from these two species were in one clade but two subgroups.

$C$. siamense has been associated with mango anthracnose in Colombia (Pardo-De la Hoz et al. 2016) and on mango fruit (Qin et al. 2017) in Sanya, Hainan province, China, and also in postharvest of mango fruits from supermarkets in Changchun, northeast China (Liu et al. 2017), but this species is not common on mango in Guangxi province, and only three isolates were found to be $C$. siamense. In this study, this species was not well separated from the C. gloeosporioides complex with the combined five genes, and more genes may be needed in future study.

Pathogenicity tests using three species of Colletotrichum isolates showed that all species were pathogenic to mango leaves and fruits in wound-inoculation studies. Symptoms may vary considerably with factors such as variety and conditions of the fruit, humidity and temperature, and the inoculum concentration (Freeman et al. 1998). Hence, the observations from this study may not reflect the full virulence potential. Additional research should be conducted to determine the virulence potential of Colletotrichum species under field conditions with natural inoculum rather than just in vitro artificial inoculation.

The Colletotrichum isolates from mango examined in this study showed diversity based on sequence analysis and morphological features. Higher genetic diversity is often correlated with higher evolutionary potential and with greater ability to adapt to changing environmental conditions (McDonald and Linde 2002). In addition, sensitivity of C. gloeosporioides and C. acutatum species from mango to carbendazim and thiabendazole are significantly different from each other in China (Hu et al. 2005). Such information can be used by pathologists and breeders to develop strategies and cultivars toward more effective management of mango anthracnose disease. Future studies should focus on surveys of more isolates and tests on other features such as fungicide sensitivity.

\section{Literature Cited}

Altschul, S. F., Gish, W., Miller, W., Myers, E. W., and Lipman, D. J. 1990. Basic local alignment search tool. J. Mol. Biol. 215:403-410.

Arauz, L. F. 2000. Mango anthracnose: Economic impact and current options for integrated management. Plant Dis. 84:600-611.

Cai, L., Hyde, K. D., Taylor, P. W. J., Weir, B., Waller, J. M., Abang, M. M., Zhang, J. Z., Yang, Y. L., Phoulivong, S., Liu, Z. Y., Prihastuti, H., Shivas, R. G., McKenzie, E. H. C., and Johnston, P. R. 2009. A polyphasic approach for studying Colletotrichum. Fungal Divers. 39:183-204.

Cannon, P. F., Damm, U., Johnston, P. R., and Weir, B. S. 2012. ColletotrichumCurrent status and future directions. Stud. Mycol. 73:181-213.

Carbone, I., and Kohn, L. 1999. A method for designing primer sets for speciation studies in filamentous ascomycetes. Mycologia 91:553-556.

Freeman, S., Katan, T., and Shabi, E. 1998. Characterization of Colletotrichum species responsible for anthracnose diseases of various fruits. Plant Dis. 82:596-605.

Freeman, S., Minz, D., Jurkevitch, E., Maymon, M., and Shabi, E. 2000. Molecular analyses of Colletotrichum species from almond and other fruits. Phytopathology 90:608-614.

Glass, N. L., and Donaldson, G. C. 1995. Development of primer sets designed for use with the PCR to amplify conserved genes from filamentous ascomycetes. Appl. Environ. Microbiol. 61:1323-1330.
Guerber, J. C., Liu, B., Correll, J. C., and Johnston, P. R. 2003. Characterization of diversity in Colletotrichum acutatum sensu lato by sequence analysis of two gene introns, mtDNA and intron RFLPs, and mating compatibility. Mycologia 95:872-895.

Hong, K., Gong, D., Zhang, L., Hu, H., Jia, Z., Gu, H., and Song, K. 2016. Transcriptome characterization and expression profiles of the related defense genes in postharvest mango fruit against Colletotrichum gloeosporioides. Gene 576:275-283.

Hu, M., Li, M., Yang, F., and Zheng, F. 2005. Biological characteristics of 2 species of Colletotrichum causing mango postharvest athracnose. Southw. China J. Agric. Sci. 18:306-310.

Hyde, K. D., Cai, L., McKenzie, E. H. C., Yang, Y. L., Zhang, J. Z., and Prihastuti, H. 2009. Colletotrichum: A catalogue of confusion. Fungal Divers. 39: 183-204.

Jayasinghe, C. K., and Fernando, T. H. P. S. 2009. First report of Colletotrichum acutatum on Mangifera indica in Sri Lanka. Ceylon J. Sci. Biol. Sci. 38:31-34.

Li, R. W., Huang, G. D., Su, M. H., Zhou, J. A., and Chen, Y. S. 2013. Status and developmental strategies of mango industry in China. J. South. Agric. 44: 875-878.

Liu, L., Shu, J., Zhang, L., Hu, R., Chen, C., Yang, L. N., Lu, B. H., Liu, Y. N., Yu, L., Wang, X., and Li, Y. 2017. First report of post-harvest anthracnose on mango (Mangifera indica) caused by Colletotrichum siamense in China. Plant Dis. 101:833.

McDonald, B. A., and Linde, C. 2002. The population genetics of plant pathogens and breeding strategies for durable resistance. Euphytica 124:163-180.

Nelson, S. C. 2008. Mango Anthracnose (Colletotrichum gloeosporiodes). Publication PD-48. Cooperative Extension Service, College of Tropical Agriculture and Human Resources, University of Hawai'i at Manoa, U.S.A.

O'Donnell, K., Nirenberg, H. I., Aoki, T., and Cigelnik, E. 2000. A multigene phylogeny of the Gibberella fujikuroi species complex: Detection of additional phylogenetically distinct species. Mycoscience 41:61-78.

Pardo-de la Hoz, C. J., Calderón, C., Rincón, A. M., Cárdenas, M., Danies, G., López-kleine, L., Restrepo S., and Jiménez, P. 2016. Species from the Colletotrichum acutatum, Colletotrichum boninense and Colletotrichum gloeosporioides species complexes associated with tree tomato and mango crops in Colombia. Plant Pathol. 65:227-237.

Peng, L. J., Sun, T., Yang, Y. L., Cai, L., Hyde, K. D., Bahkali, A. H., and Liu, Z. Y. 2013. Colletotrichum species on grape in Guizhou and Yunnan provinces, China. Mycoscience 54:29-41.

Photita, W., Taylor, P. W., Ford, R., Hyde, K. D., and Lumyong, S. 2005 Morphological and molecular characterization of Colletotrichum species from herbaceous plants in Thailand. Fungal Divers. 18:117-133.

Phoulivong, S., Cai, L., Chen, H., McKenzie, E. H., Abdelsalam, K., Chukeatirote, E., and Hyde, K. D. 2010. Colletotrichum gloeosporioides is not a common pathogen on tropical fruits. Fungal Divers. 44:33-43.

Qin, L. P., Huang, S. L., Lin, S. H., and Lin, C. H. 2017. First report of anthracnose of Mangifera indica caused by Colletotrichum siamense in Sanya city in China. Plant Dis. 101:1038.

Sharma, G., Gryzenhout, M., Hyde, K. D., Pinnaka, A. K., and Shenoy, B. D. 2015. First report of Colletotrichum asianum causing mango anthracnose in South Africa. Plant Dis. 99:725.

Taylor, B. H., Manhart, J. R., and Amasino, R. M. 1993. Isolation and characterization of plant DNAs. Pages 37-65 in: Methods in Plant Molecular Biology and Biotechnology. B. R. Glick and J. E. Thompson, eds. CRC Press, Boca Raton, FL.

Templeton, M. D., Rikkerink, E. H., Solon, S. L., and Crowhurst, R. N. 1992 Cloning and molecular characterization of the glyceraldehyde-3-phosphate dehydrogenase-encoding gene and cDNA from the plant pathogenic fungus Glomerella cingulata. Gene 122:225-230.

Valero, M., García-Martínez, S., Giner, M. J., Alonso, A., and Ruiz, J. J. 2010 Benomyl sensitivity assays and species-specific PCR reactions highlight association of two Colletotrichum gloeosporioides types and $C$. acutatum with rumple disease on Primofiori lemons. Eur. J. Plant Pathol. 127: 399-405.

Vieira, W. A., Michereff, S. J., de Morais, M. A., Jr., Hyde, K. D., and Câmara, M. P. 2014. Endophytic species of Colletotrichum associated with mango in northeastern Brazil. Fungal Divers. 67:181-202.

Weir, B. S., Johnston, P. R., and Damm, U. 2012. The Colletotrichum gloeosporioides species complex. Stud. Mycol. 73:115-180.

White, T. J., Bruns, T., Lee, S. J. W. T., and Taylor, J. W. 1990. Amplification and direct sequencing of fungal ribosomal RNA genes for phylogenetics. Pages 315-322 in: PCR Protocols: A Guide to Methods and Applications. M. Innis, D. Gelfand, J. Sninsky, and T. White, eds. Academic Press, San Diego, CA. 